\title{
West African monsoon precipitation impacted by the South Eastern Atlantic biomass burning aerosol outflow
}

\author{
F. Solmon $\mathbb{D}^{1 凶}$, N. Elguindi ${ }^{1}$, M. Mallet ${ }^{2}$, C. Flamant $\mathbb{D}^{3}$ and P. Formenti ${ }^{4}$
}

The West African Monsoon (WAM) is a complex system depending on global climate influences and multiple regional environmental factors. Central and Southern African biomass-burning (SABB) aerosols have been shown to perturb WAM during episodic northward inter-hemispheric transport events, but a possible dynamical connection between the core of the SABB aerosol outflow and the WAM system remains unexplored. Through regional climate modeling experiments, we show that SABB aerosols can indeed impact WAM dynamics via two competitive regional scale and inter-hemispheric dynamical feedbacks originating from (i) enhanced diabatic heating occurring in the Southeastern Atlantic low-cloud deck region, and (ii) aerosol and cloud-induced sea surface temperature cooling. These mechanisms, related to aerosol direct, semi-direct, and indirect effects, are shown to have different seasonal timings, resulting in a reduction of June to September WAM precipitation, while possibly enhancing late-season rainfall in WAM coastal areas.

npj Climate and Atmospheric Science (2021)4:54; https://doi.org/10.1038/s41612-021-00210-w

\section{INTRODUCTION}

The understanding of climate variability in West Africa is of prime importance for regional socioeconomic sustainability, especially in the context of climate change and population growth. Since the dramatic Sahelian droughts of the eighties, much effort has been devoted to a better scientific understanding and modeling of the West African Monsoon (WAM) system and its connection to global dynamics and to regional factors, including anthropogenic perturbations ${ }^{1}$. For example, at the regional scale, the Saharan heat low and the South East Atlantic (SEA) cold tongue intensity, land-use changes, and soil moisture feedbacks are important for the meridional distribution of diabatic and moisture sources impacting the WAM regional moist static energy gradient, convective activity, and rainfall ${ }^{2}$. Absorbing aerosol particles, which are emitted both naturally and as a result of anthropgenic activity in large quantity over Africa, may also impact monsoon dynamics through complex interactions with solar and thermal radiation, and with clouds through microphysical effects. The impact of mineral dusts present over the Sahara and Sahel during the June to September (JJAS) WAM season has received much attention in studies covering a broad range of spatial and temporal scales ${ }^{3-6}$, On the contrary, possible impacts of biomass-burning aerosol emissions, which are mostly active over southern hemisphere Africa during the WAM season, have received less attention. A few studies have nevertheless suggested continental-scale connections between the central and southern Africa biomass-burning (SABB) aerosol radiative forcing and tropical Africa precipitation, mostly attributed to the perturbation of continental static stability ${ }^{7}$. Recent studies have also pointed out that a fraction of SABB particles, once northwardly advected over West Africa, could contribute to impacting the local climate via cloud interactions ${ }^{8}$ or modification of local atmospheric stability $^{9,10}$, Here, we show that SABB can also have an important effect on WAM through a regional inter-hemispheric dynamical feedback originating from the highly concentrated SABB aerosol outflow located over the South Eastern Atlantic (SEA) ocean (Fig. 1, region $A$ ). This impact is shown to be associated with the SEA semi-permanent stratocumulus cloud cover and involves atmospheric fast adjustment vs. slower sea surface temperature (SST) response to aerosol perturbation ${ }^{11}$. Over recent years, the SABB aerosol outflow region has received much scientific attention notably through the Aerosol Radiation and CLOuds in Southern Africa AEROCLO-sA ${ }^{12}$, the ObseRvations of Aerosols Clouds and their interactions ORACLES ${ }^{13}$, the Clouds and Aerosol Radiative Impacts and Forcing CLARIFY ${ }^{14}$, and the Dynamics-AerosolChemistry-Cloud Interactions in West Africa DACCIWA ${ }^{8}$ programs. The combination of new observations and state-of-the-art models (see e.g., ${ }^{15}$.) implemented in these programs are shedding new light on the SEA aerosol outflow properties and its interaction with low-level clouds.

In this context, we use a suite of regional climate simulations to explore the role of several regional scale interaction mechanisms between SABB aerosol, clouds, SST, and WAM dynamics. Numerical experiments are performed using the RegCM4 model ${ }^{16}$ on a large pan-African domain covering the period from 2002 to 2015 and makes use of an interactive aerosol scheme, and a slab ocean model (Methods) ${ }^{17}$. present a detailed evaluation of the RegCM4 baseline simulations (described as AERSLAB in Methods), based on updated cloud and aerosol observations in the SEA outflow, and an inter-comparison with a higher resolution regional climate model. Complementary model evaluations regarding WAM precipitation and dynamics are also reported in the Supplementary Notes. Despite specific biases discussed in ${ }^{17}$ and (Supplementary Notes), we consider that key aspects of WAM, SEA cloud cover, and SABB aerosol outflow are reasonably captured on the climatic time scale. Starting from the baseline model configuration, additional sensitivity experiments (described in

\footnotetext{
${ }^{1}$ Laboratoire d'Aérologie, UMR 5560 CNRS, Observatoire Midi-Pyrénées, Université de Toulouse, Toulouse, France. ${ }^{2}$ Centre National de La Recherche Météorologique, MétéoFrance, Toulouse, France. ${ }^{3}$ Laboratoire Atmosphères, Milieux, Observations Spatiales (UMR 8190 CNRS), IPSL, Sorbonne Université, Paris, France. ${ }^{4}$ Laboratoire Interuniversitaire des Systèmes Atmosphériques (LISA), UMR CNRS 7583, Université Paris-Est-Créteil, Université de Paris, Institut Pierre Simon Laplace, Créteil, France. ${ }^{\circledR}$ email: fabien.solmon@aero.obsmip.fr
} 


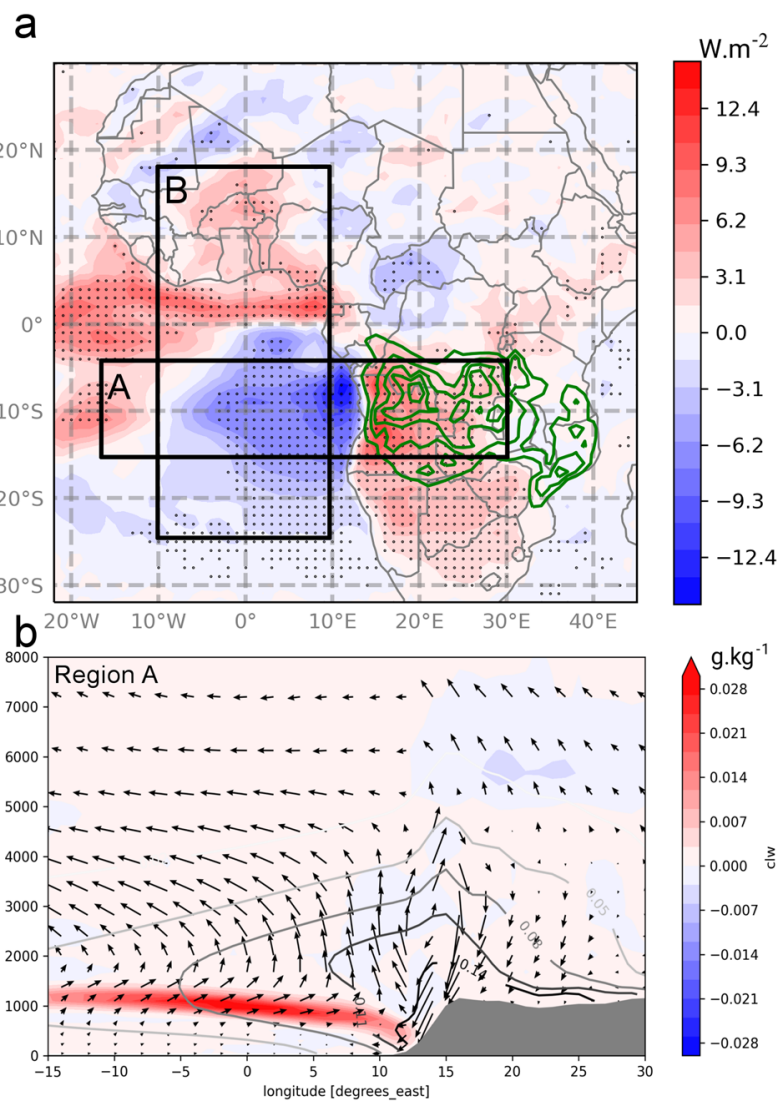

Fig. 1 SABB aerosol-induced semi-direct effect and dynamical feedback. a TOA Shortwave semi-direct effect (SDE) induced by SABB aerosol for the period JJAS 2003-2015. The green contours represent the mean JJAS GFED4 biomass-burning emission region for black carbon flux iso-contour levels of $10,20,30,40,50 \mathrm{ng} \mathrm{m}^{-2} \mathrm{~s}^{-1}$. Box $A$ represents the region of analysis encompassing continental $\mathrm{SABB}$ sources and aerosol outflow to the SEA. Box B represents the region of analysis encompassing the WAM domain and the SEA aerosol outflow. Dotted regions represent areas where SDE significantly differs from DE only. $\mathbf{b}$ Zonal cross-section plotted over region A representing the meridional and JJAS 2003-2015 average of SABB aerosol extinction (contours in $\mathrm{km}^{-1}$ ), circulation anomaly (normalized arrows), and cloud liquid water mixing ratio anomaly. Anomaly calculations are based on the difference between a perturbation run including standard aerosol species and SABB particles, and a control run including standard aerosol species without SABB particles.

Methods and along the following sections) are used for further analysis of the SABB aerosol impacts.

\section{RESULTS}

\section{SABB aerosol semi-direct effect and impacts on regional} circulation

The SABB aerosol semi-direct effect (SDE) quantifies the top of atmosphere (TOA) radiative changes associated with cloud adjustments to aerosol radiative perturbation (Methods). The aerosol perturbation is itself quantified by the direct effect (DE), which does not include any cloud adjustment (Methods). Considered together, DE and SDE can be used to assess the effective aerosol radiative climate forcing and to evaluate and inter-compare climate model sensitivities to aerosol effects ${ }^{18}$. By nature, SDE is associated with dynamical and thermodynamical changes that we seek to better understand hereafter for impact assessments.
Focusing first on the region including SABB sources and the SEA aerosol outflow (region A, Fig. 1), the SDE calculated from the baseline AERSLAB experiment (Methods) shows a sharp zonal land-ocean contrast. Over the SEA, a radiative cooling is obtained due to an increase of the low-level cloud water content and cloud fraction when SABB particles are accounted for (Fig. 1a, b). The low-level cloud feedback mostly results from the diabatic heating produced by shortwave absorption in the SABB aerosol layer, materialized by extinction contours in Fig. 1b, in relationship with a positive DE above the bright low-level cloud deck (see Supplementary Figure $1 \mathrm{a}$ and ${ }^{17}$ ). This heating is associated with an increase in above-cloud air buoyancy and a relative reduction of above-cloud subsidence (upward circulation anomaly in Fig. 1b) and associated dry air intrusions. This translates into an increase of low-level cloud liquid water content on the zonal cross-section displayed in Fig. 1b. The low-level cloud increase is also reinforced by an increase in boundary layer stability associated with decreasing SST response (Supplementary Figure 1d). Similar lowlevel cloud feedbacks have been discussed in several studies based on both observations and multi-scale model analyses ${ }^{19,20,7}$, Over SEA, the negative SDE compensates for the positive DE resulting in a negative effective radiative effect of about $-1.7 \mathrm{~W}$ $\mathrm{m}^{-2}$ during JJAS in the outflow box region $\left(-10^{\circ} \mathrm{E} ;-10^{\circ} \mathrm{W},-20^{\circ} \mathrm{S}\right.$; $-5^{\circ} \mathrm{S}$ ), a result which is consistent with ${ }^{21,22}$, On the continental part of region A, shortwave SDE is positive due to a reduction of mid- to high-level cloudiness and convective activity (Fig. 1b) consecutive to aerosol solar diming, surface cooling and lower troposphere stabilization (see downward vertical wind anomaly on Fig. 1b). In the SABB aerosol source region (i.e., over the continental part of region $A$ ), this stabilization effect dominates over absorption and diabatic heating effect so that precipitation is reduced (Supplementary Figure 1c), consistently with ${ }^{23,24,7}$, The contrast between the continental and the maritime responses to $S A B B$ aerosol lies primarily in the difference of surface albedo (including here the cloudy marine boundary layer), which drives an abrupt change of critical single scattering albedo and a switch of the SABB aerosol DE sign from negative (continent) to positive (low-level clouds over ocean). When accounting for longwave radiation (Supplementary Figure $1 \mathrm{~b}$ ), the total SDE patterns are not modified much in region $A$. Based on global modeling experiments ${ }^{18}$, found a large contribution of high-cloud adjustments and associated longwave cooling changes to the total SDE over central and southern Africa. Our regional approach shows an existing, but weaker high-level cloud response, SDE being driven essentially by low- and mid-level cloud adjustments impacting predominantly the shortwave radiative budget.

Another region showing a robust positive SDE signal is the southern part of West Africa belonging to region B on Fig. 1. During the JJAS wet season, West Africa is not a dominant biomass-burning source region, so this signal is likely to result from a larger regional scale circulation adjustment to SABB aerosol radiative effects, in contrast to the more local effects discussed for region $A$. This is confirmed when analyzing the vertical cross sections of circulation anomaly induced by SABB aerosol in the $A E R S L A B$ experiments (see Fig. 2a). In the SABB outflow, where regions $A$ and $B$ overlap, we can identify the previously discussed ascending branch triggered by large aerosol diabatic heating. Northward, there is a counterpart descending branch, over the coastal region of West Africa. This subsiding anomaly is associated with a decrease of convective heating rate anomaly (and so parameterized convective cloudiness, Fig. 2d), and a slight decrease of mid-level cloud liquid water content (Fig. 2a). Both of these negative anomalies translate into a decrease of the precipitation rates over coastal southern West Africa from $10 \mathrm{~N}$ to $5 \mathrm{~S}$ (Fig. 2g). This drying signal can be interpreted as a remote regional effect of SABB aerosol emission activity. Both the decrease in convective cloudiness (Fig. 2d, e) and mid-level cloud liquid water content (Fig. 2a) explain the positive SDE obtained in 

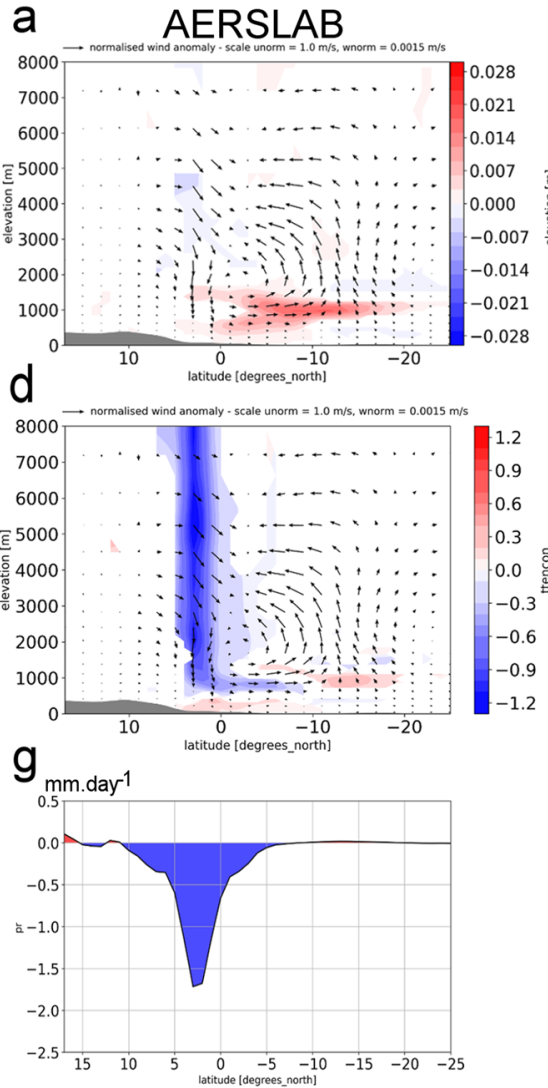

b
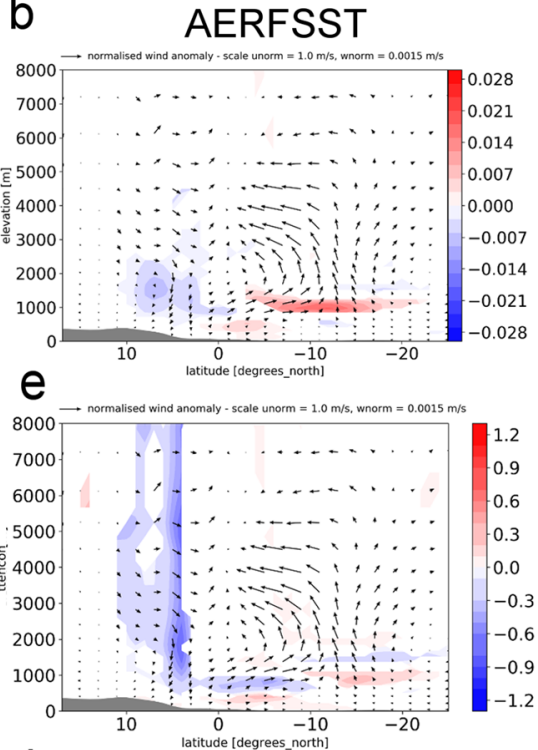

h

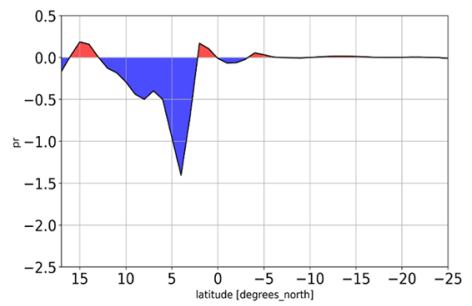

C ANOSST
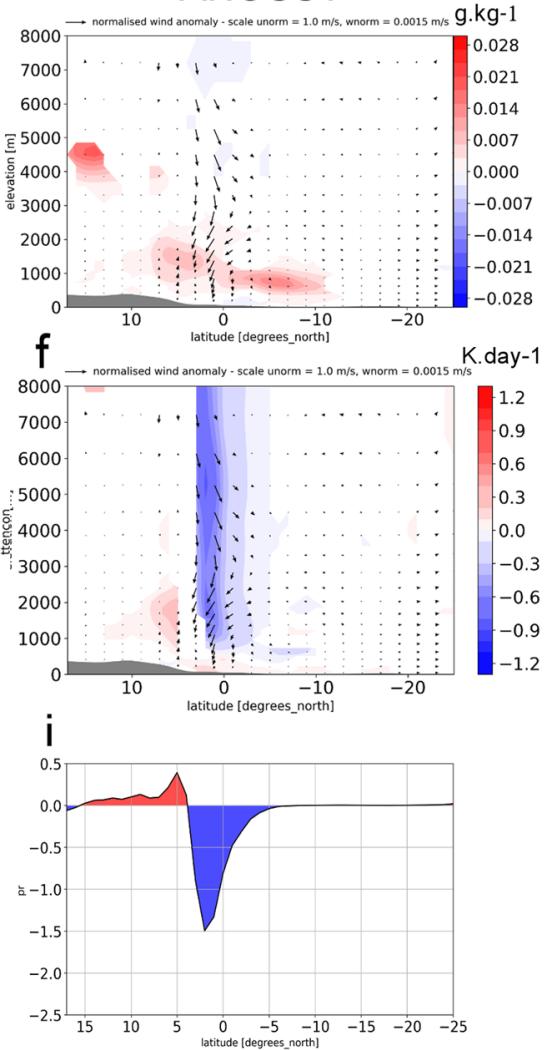

Fig. 2 Impact of SABB aerosol on WAM dynamics, clouds, convection and precipitation. Mean JJAS 2003-2015 meridional cross sections of SABB aerosol-induced anomalies calculated over region $B$ (considering a $10^{\circ} \mathrm{W}-10^{\circ} \mathrm{E}$ zonal mean) respectively for the $A E R S L A B, A E R F S S T$ and ANOSST experiments: $(\mathbf{a}, \mathbf{b}, \mathbf{c})$ meridional circulation and cloud water mixing ratio anomaly, (d, e, f) meridional circulation and convective heating rate anomaly, $(\mathbf{g}, \mathbf{h}, \mathbf{i})$ precipitation anomaly. Anomaly calculations are based on the difference between a perturbation run including standard aerosol species and SABB particles, and a control run including standard aerosol species without SABB particles. Only statistically significant anomalies are plotted for cloud water, convective tendencies, and precipitation (cf Methods).

region B of Fig. 1a over the Gulf of Guinea and continental West Africa, and is associated with dryer and warmer conditions under the descending branch. When including longwave radiation (Supplementary Figure 1b), the positive shortwave SDE signal over West Africa is partly compensated by the reduction of highlevel cloudiness resulting in more longwave cooling at the top of the atmosphere. For convenience in the following discussion, the above described meridional circulation anomaly and climate feedback, which originate from SABB aerosol anomalous shortwave diabatic heating will be referred as the Aerosol Diabatic Heating Feedback (ADHF).

A question arising at this point is to what extent aerosol radiative forcing over continental southern Africa, which is larger in magnitude than over the SEA, can impact the above results. The additional AERSEAONLY experiment (Methods), suggests that the ADHF and meridian precipitation anomaly over the WAM domain are not fundamentally changed (in sign and position, Fig. 2a, d, g and Supplementary Fig. 3a, c, e) when the continental part of $\mathrm{SABB}$ aerosol radiative forcing is removed. However, the signal magnitude is affected, with convective heating and precipitation anomalies being larger by about $30 \%$ in the AERSLAB experiment with respect to the AERSEAONLY experiment. The conclusions of this experiment are that $i$ ) the $S A B B$ aerosol diabatic warming and the ADHF triggered in the SEA outflow, which depend on a lowlevel cloud deck presence and feedback, are of prime importance for the impact on WAM, and ii) that the continental SABB aerosol radiative forcing, while likely inducing the dry anomaly over southern Africa through increased stability ${ }^{7}$, might only be a secondary contributor to the drying obtained over the WAM domain.

\section{Role of aerosol-induced SST perturbation}

So far, we considered the aerosol solar absorption above the SEA cloud deck as the only driver of the regional climatic response impacting WAM. However, surface solar dimming resulting from direct and semi-direct effects may also affect SST and play a role in this response. Based on the AERSLAB experiment, we estimate that $\mathrm{SABB}$ aerosol induce a SST cooling that can reach up to $-1.3 \mathrm{~K}$ over SEA (Figures S1d and 3). Both the amplitude and spatial pattern of this signal are consistent with ${ }^{7}$. The SST response includes not only the SABB aerosol direct forcing but also the positive low-level cloud feedback which further increases solar dimming at the surface. To investigate the role of SST adjustment response vs. the ADHF mechanism, we compare results from (i) the AERFSST experiment in which SSTs are forced by reanalysis and thus not sensitive to $\mathrm{SABB}$ aerosol and cloud radiative perturbations (Methods), and (ii) the ANOSST experiment which only accounts for feedbacks generated through the SST cooling induced by aerosol and low-level cloud perturbation, while not considering anomalous diabatic heating in the SABB layer.

Figure 2 displays the meridional circulation, large-scale cloud liquid water content, convective heating rate. and precipitation anomalies obtained for each experiment in region $B$. In the AERFSST experiment (Fig. 2b, e, h), the ADHF pattern is still clearly identified and associated with a southward anomalous circulation in the lower troposphere, i.e., opposed to the climatological 
monsoon flow (Fig. $2 \mathrm{~b}$ and S5a). Convective activity and precipitation reduction are mostly reduced north of $2.5^{\circ} \mathrm{N}$ Fig. $2 \mathrm{e}, \mathrm{h}$ ), with a drying effect overland from $5^{\circ} \mathrm{N}$ to $13^{\circ} \mathrm{N}$, slightly more pronounced than in the AERSLAB case. The response obtained in the ANOSST experiment is significantly different in terms of latitudinal positioning (Fig. 2c, f, i). There is no more ADHF-like pattern identified, while convective activity and precipitation tend to be shifted northward with wetter continental conditions. The anomalous flow in the lower troposphere is northward between $5^{\circ} \mathrm{S}$ and $7.5^{\circ} \mathrm{N}$, contributing to enhance moisture transport to the WAM coastal area. In summary, the aerosol-induced SST perturbation triggers a sea breeze like feedback driven by a sharpening of meridional low-level thermal gradient between a colder ocean and the continent (an effect qualitatively similar to the Atlantic cold tongue installation ${ }^{25,26}$,

Between $15^{\circ} \mathrm{N}$ and $5^{\circ} \mathrm{S}$, we note that both the position and intensity of the anomalous precipitation pattern obtained with the $A E R S L A B$ experiment can almost be reproduced by the addition of the competitive ADHF and SST cooling feedback (SSTCF) obtained in the AERFSST and ANOSST experiments, respectively (see Supplementary Fig. 3). Considering continental precipitation in West Africa, the ADHF tends to decrease precipitation while the SSTCF tends to increase them, especially over the coastal area. Over the full monsoon season, our results suggest that the ADHF impact is dominant and results in dryer JJAS conditions, with a statistically significant reduction of precipitation in the coastal WAM region of up to $-12 \%$ (calculated in a box $10^{\circ} \mathrm{W}-10^{\circ} \mathrm{E}, 0-5^{\circ}$ $\mathrm{N}$, and considering baseline AERSLAB JJAS precipitation larger than $2 \mathrm{~mm} /$ day). The timing of these feedbacks and their effective impact on precipitation throughout the wet season is discussed further.

\section{Contribution of aerosol indirect effects}

There is still a debate on the importance of SABB aerosol indirect effects on low-level clouds. Some recent studies ${ }^{22,20}$, argue that semi-direct effect is predominant over the indirect effects over SEA while others ${ }^{27}$ suggest that aerosol intrusions in low-level cloud and associated indirect effects could be important regarding aerosol effective radiative forcing and feedbacks in the SEA. In order to assess how indirect effects could modify the previously described mechanisms, we considered an additional experiment where SABB aerosols interact with cloud droplet effective radius and auto conversion rates through simplified approaches (experiment AERIND described Methods). Supplementary Fig. $3 b, d, f$ displays the anomalies obtained in the AERIND for comparison to the baseline AERSLAB case (Fig. 2). Our result suggests that meridional circulation, cloud, convection, and rainfall anomalies are not much modified in term of pattern and position, but are significantly amplified. We attribute this amplification to (i) increasing low-level cloud albedo due to in cloud SABB aerosol, which enhances above-cloud SABB aerosol radiative warming in the core outflow, and (ii) a decrease in surface incoming solar radiation due to enhanced cloud extinction (resulting from indirect effects) and an induced stabilization in convective regions of the Guinea Gulf notably. The slight enhancement of convection and precipitation on West African continental areas could also be the signature of a slightly enhanced SSTCF occurring due to slightly colder SSTs when the aerosol indirect effect is at play (see also next section). As reported $\mathrm{in}^{28}$, our results suggest that the simulated first indirect effect is dominant over the second indirect effect. Overall, it contributes to reinforce the feedbacks driven by direct and semi-directs effects on the domain. In term of magnitude, the indirect effect contribution shall be taken with caution, due to a rather simplified representation of complex cloud and aerosol microphysical processes at play (cf Discussion).

\section{Temporal aspects of SABB aerosol impact on WAM}

The analysis of aerosol SDE at the global scale often distinguishes between a fast atmospheric response, usually evaluated by mean of forced SST experiments ${ }^{11}$, and a slow response accounting for the climatic adjustment of SST and calculated using fully coupled simulation responses ${ }^{29}$. In our study, the aerosol-induced SST perturbation is seasonally impacted by the slab ocean mixed layer inertia: In Fig. 3, we can see that the SEA surface shortwave radiation anomaly resulting from $\mathrm{SABB}$ aerosol extinction and cloud adjustments starts in June and peaks in August-September, corresponding to maximum BB activity in southern hemisphere Africa, while the maximum SEA SST cooling is obtained about 2 months later. Figure 3 also shows the effect of northern hemisphere biomass-burning aerosol emissions peaking from December to February, inducing a SST cooling between 0 and $5^{\circ} \mathrm{N}$ in the Guinea Gulf. In our simulations, these seasonal perturbations have a residual SST cooling effect throughout the year. As a

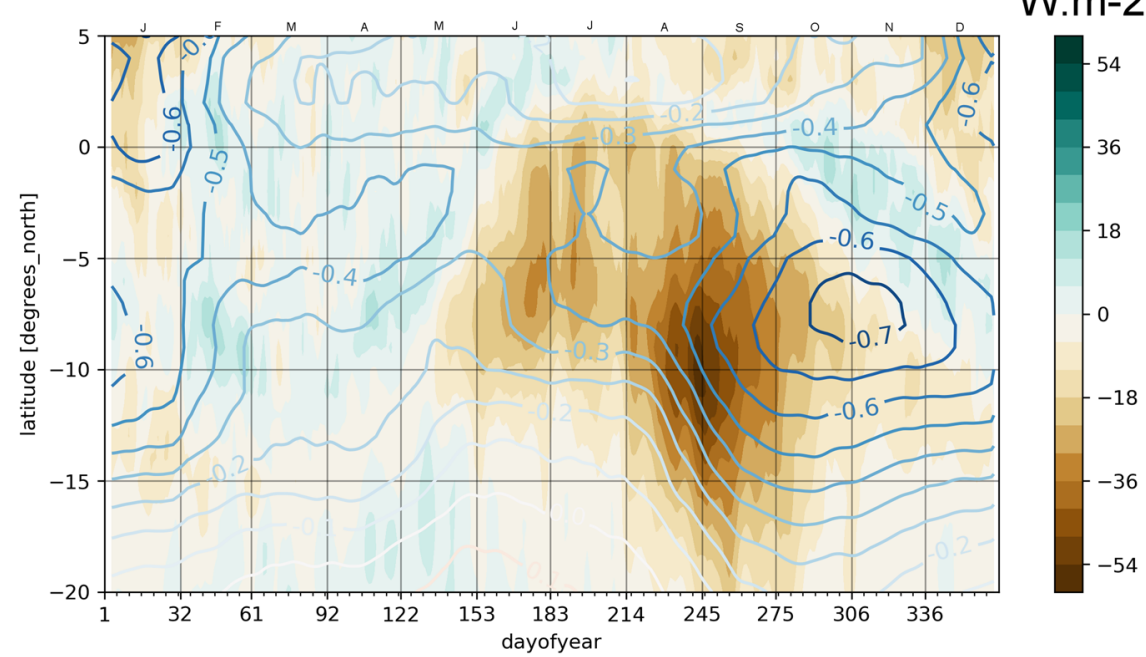

Fig. 3 SABB aerosol impact on shortwave radiation and SST over the SEA. Time-latitude Hovmoller diagram of mean $2003-2015$ daily SABB aerosol-induced surface shortwave radiation anomaly (color contours), and SST anomaly (solid contours). Anomalies are zonally averaged over $10^{\circ} \mathrm{W}-10^{\circ} \mathrm{E}$ (corresponding to Fig. 1, Region B) and are calculated from the AERSLAB experiment perturbed and control runs. The SST cooling response in the SEA is delayed by about 2 months compared to the peak of surface shortwave negative anomaly. 

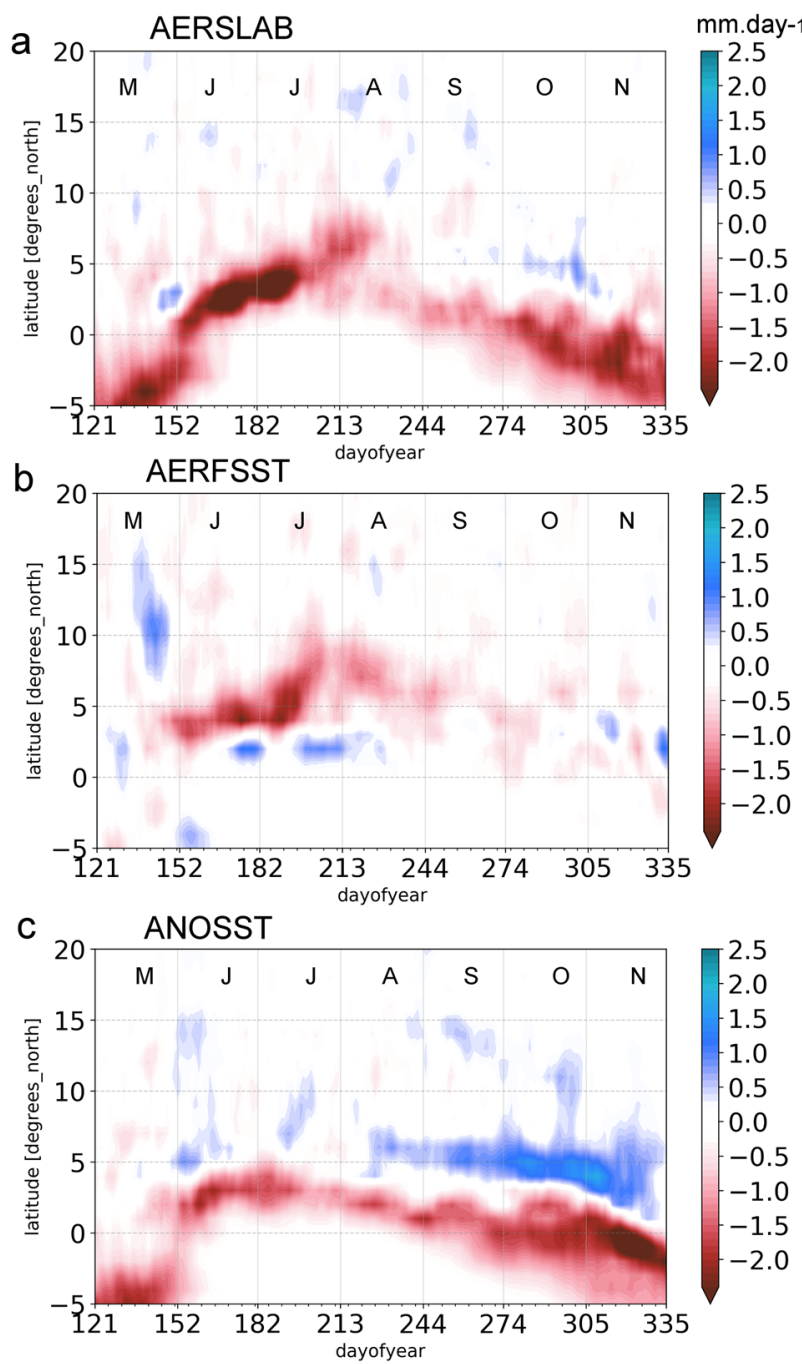

Fig. 4 SABB aerosol impact on precipitation evolution during the WAM season. Time latitude Hovmoller diagram (covering May to November) of mean 2003-2015 daily SABB aerosol-induced precipitation anomalies (zonally averaged over $10^{\circ} \mathrm{W}-10^{\circ} \mathrm{E}$ ) for: a the $A E R S L A B$ experiment which illustrates the effective impact of SABB aerosol on precipitation, $\mathbf{b}$ the AERFSST experiment which illustrates the feedback associated to SABB aerosol diabatic heating, and $\mathbf{c}$ the ANOSST experiment which illustrates the feedback associated to SABB aerosol-induced SST cooling.

result of this delayed SST response, the relative contributions of the ADHF, associated to the AERFSST experiment (Fig. 4b), and the SSTCF, associated to the ANOSST experiment (Fig. 4c), to the baseline AERSLAB precipitation anomaly (Fig. $4 \mathrm{a}$ ) are variable in time. Particularly, Fig. 4c suggests that the SSTCF is more effective towards the end of the WAM season. The influence of SSTCF and the associated positive precipitation anomaly is also detectable in the AERSLAB experiment, between October and November (Fig. 4a). This result suggests that SABB aerosol could contribute to enhance precipitation during the secondary rainy season which occurs during September-November over coastal southern West Africa $^{30}$. On the contrary, the fast response occurring through the ADHF is dominant from June to mid-September, resulting in a negative precipitation anomaly at the JJAS seasonal scale (Figs. 4a, b). Nevertheless, due to the persistence of the SST perturbation, our simulations suggest that the SSTCF still contributes to dampen the ADHF even earlier in the WAM season. Taking into account the SABB aerosol indirect effects in the AERIND experiment does not modify much the structure of the seasonal anomaly pattern
(Supplementary Figure 4 to be compared with Fig. 4a). However, as mentioned and discussed earlier, we can note that both the magnitude of drying and late-season rainfall enhancement over land are amplified compared to the AERSLAB baseline.

\section{DISCUSSION}

In this study, we describe mechanisms by which SABB aerosols are likely to modulate the WAM dynamics and precipitation over southern West Africa. Particularly, these results provide causal relationships compatible with the recent observation-based analysis of ${ }^{9,31}$, outlining notably a link between inter-hemispheric aerosol transport, AOD anomaly, and negative precipitation anomaly in the southern WAM coastal area. Using model sensitivity tests, we furthermore suggest that, at a climatic scale, SABB aerosol-induced convection and precipitation suppression in the WAM coastal area is primarily a result of a regional scale dynamical adjustment triggered by the large positive SABB aerosol radiative forcing in the SEA outflow and over the stratocumulus deck region. When isolating the feedbacks occurring through the regional SST slow response, we show that, in addition to inhibiting precipitation via local stabilization $^{32}$ in the Guinea Gulf, the SABB aerosol-induced SST cooling could promote enhanced continental precipitation via sharpened land-sea contrast. This effect is stronger towards the end of the WAM season.

The balance between the ADHF and the SSTCF depends, however, on a number of factors. First, the simulated low-level cloud and SABB aerosol properties and interactions play a key role in determining the relative magnitude of atmospheric heating and SST cooling which are fueling the ADHF and SSTCF mechanisms. The recent ORACLES, CLARIFY-2017, and AEROCLO-sA campaigns have notably shown that $S A B B$ aerosol particles are more absorbing than previously thought ${ }^{33}$. Measurements made by ${ }^{34}$ highlight that smoke aerosol single scattering albedo could be as low as 0.75 (at $550 \mathrm{~nm}$ ), when RegCM4 simulated values are about 0.88 during JJAS. Combined with the fact that simulated abovecloud AOD are slightly underestimated (Supplementary Notes), the simulated $S A B B$ aerosol solar absorption and heating rates might fall on a lower end compared to real situations. In this regard, the ADHF- and CSSTF-related impacts could be even larger, but this also depends on the realism of simulated lowclouds. Second, based on the AERIND sensitivity experiment, we suggest that the SABB aerosol first indirect effect on SEA and Guinea Gulf low-level clouds is likely to strengthen the direct and semi-direct induced anomalies. There are however potentially large uncertainties in this regard, notably concerning the impact of the SABB aerosol second indirect effect on WAM convective clouds at climatic time scale s5,36 $^{3}$ well as stratocumulus and convective cloud adjustments reacting to direct and indirect perturbation in terms of diurnal cycles ${ }^{37}$, cloud cell dynamics ${ }^{38}$ and transition to cumulus regime ${ }^{39}$. All these feedbacks can affect in return marine boundary layer albedo, aerosol radiative forcing, and effective aerosol impacts on WAM. Third, we acknowledge that a slab ocean approach might oversimplify the response of SST to aerosol and cloud cover perturbation. Regional circulation complexity and atmosphere-ocean interactions, which are recognized to be significant sources of biases in climate model ${ }^{26}$, are likely to modify SST responses. For instance, a possible mixed layer depth overestimation in the Guinea gulf (Methods) could result in a local underestimation of the SST response and the magnitude of the SSTCF. The use of a fully interactive high-resolution ocean model would likely help to refine regional effective SST response and the SSTCF mechanism depicted in this study. Finally, although that our experiments run over several years and that simulated feedbacks have been tested for statistical significance, model internal variability can still impact our results to some extent. Gaining more robustness on the aerosol-induced signal quantification would require a large simulation ensemble for each of the experiments considered here. 


\section{METHODS \\ Model configuration}

We use the International Center for Theoretical Physics (ICTP) regional climate model RegCM4 ${ }^{16}$ at $80 \mathrm{~km}$ horizontal resolution and with 42 vertical levels extending from the surface to $50 \mathrm{hPa}$, with a refined grid in the lower troposphere and the boundary layer. Runs are performed on a pan-African domain $\left(35^{\circ} \mathrm{S}-30^{\circ} \mathrm{N} ;-30^{\circ} \mathrm{W}-45^{\circ} \mathrm{E}\right)$ over the period $2002-2015$, including a one year spin up. Lateral boundary conditions are provided by ERA-Interim ${ }^{40}$ reanalysis. The simulation domain is considered large enough to allow for meridional dynamical feedbacks to develop, while global scale adjustments (zonal waves notably) cannot be fully accounted for. The main physics options used for this study are listed in (Supplementary Methods). As described in $^{17}$, the RegCM4 aerosol scheme includes a bulk representation of anthropogenic sulfate, black and organic carbon particles as well as natural sea-salt and dust aerosol emission and transport schemes. Biomass-burning carbonaceous aerosol is simulated using two specific smoke tracers corresponding to fresh and aged particles. The optical properties of these particles are discussed in (Supplementary Information). Daily biomass-burning emissions issued from the Global Fire Emission Data Base version $4^{41}$ are prescribed to the model, including emission correction factors ${ }^{17}$. All aerosol particles can induce feedbacks to meteorology and climate through the radiative transfer scheme. Both the aerosol and multiphase cloud microphysics schemes used in this study are based on a single moment representation ${ }^{42}$. Aerosol indirect effects can be activated through modification of cloud droplet effective radius and cloud water to rainwater auto-conversion depending on hydrophilic species concentrations. The calculation of representative CCN concentration from aerosol concentration relies on simplified empirical relationships, initially developed for sulfate and linking bulk hydrophilic aerosol concentrations to CCN number concentration ${ }^{28}$. The slab ocean parameterization is based on a 50-m deep ocean mixed layer energy budget. This depth is consistent with climatological values reported $\mathrm{in}^{43}$ for the SABB aerosol outflow region, but tends to be overestimated for the Gulf of Guinea region. Large-scale driven SST seasonal cycle is kept nondivergent and realistic using a flux-correction term built from Optimum Interpolation Sea Surface Temperature (OISST) observations $^{44}$ and a restore run technique as described in ${ }^{45}$. Aerosol- and cloudinduced perturbations of the mixed layer energy budget occur through modification of incoming surface radiation and meteorological adjustments (e.g., wind), but the resulting impact on SST depends also on the corrective flux regional pattern.

\section{Numerical experiments}

Five sets of numerical experiments are carried out. They consist each in a control run including standard aerosol but excluding SABB aerosol, and a perturbed run including standard aerosol and SABB aerosol. In our analysis, $\mathrm{SABB}$ aerosol-induced anomalies refer to differences between the perturbed and control runs. The five experiments are:

(i) The baseline AERSLAB experiment, which is performed using the slab ocean model. These runs are tested against observations in ${ }^{17}$ and (Supplementary Notes),

(ii) The AERFSST experiment, where the model is directly forced by OISST instead of the interactive slab ocean model,

(iii) The ANOSST experiment, where the perturbed run is built using SST anomalies obtained from the AERSLAB experiment added to OISST, while considering no atmospheric diabatic effect of biomassburning aerosol. The control run is identical to AERFSST control,

(iv) The AERSEAONLY experiment uses the slab ocean model similarly to AERSLAB but in the perturbed run, SABB aerosol radiative properties are set to zero over land, meaning that only the maritime part of the $\mathrm{SABB}$ aerosol plume is causing the radiative perturbation.

(v) The AERIND experiment, which is based on the AERSLAB configuration but include also aerosol indirect effects triggered by hydrophilic species in the control and perturbation experiment. For this later, only hydrophilic SABB smoke tracer generates indirect effects.

\section{Semi-direct effect calculation}

Following ${ }^{20,46}$, the SABB aerosol DE and SDE are calculated at TOA from the control and perturbed run of the baseline AERSLAB experiment as:

$\mathrm{DE}=\left(F-F_{\text {clean }}\right)_{\text {pert }}-\left(F-F_{\text {clean }}\right)_{\text {ctl }}$

$\mathrm{SDE}=\left(F_{\text {pert }}-F_{\mathrm{ctl}}\right)-\mathrm{DE}$

where $F$ refers to either to TOA net shortwave, or total (shortwave + longwave) radiative flux, while $c t l$, and pert refer to control and perturbed simulations, respectively. For a given run, $F-F_{\text {clean }}$ represents TOA radiative forcing resulting from the aerosol species considered in this run. This diagnostic is calculated using a double call to the radiation scheme during the integration and $F_{\text {clean }}$ refers to the call where all aerosol concentrations are set to zero. The direct effect of SABB aerosol (DE) thus corresponds to the difference between the perturbed and control TOA aerosol radiative forcings, while $\left(F_{\text {pert }}-F_{\text {ctl }}\right)$ represents the effective radiative forcing of $S A B B$ aerosol which includes climatic feedback TOA radiative signatures. We chose to present shortwave SDE in Fig. 1 because it straightforwardly illustrates cloud changes, while total SDE is more complex to interpret since the LW component is more sensitive to the type of cloud involved.

\section{Statistical significance tests}

Statistical significance of anomalies and differences reported in Figures and Supplementary Figures are based on a grid-cell level Student's $t$ test considering a $95 \%$ confidence interval.

\section{DATA AVAILABILITY}

Model output data (daily or monthly averages) can be obtained from the corresponding author upon request. All observations, reanalysis and aerosol emission data sets used in this study are publically available (see specific references).

\section{CODE AVAILABILITY}

The RegCM4 code and related forcing fields can be downloaded through https:// github.com/ictp-esp/RegCM. Specific model setups, and post-processing scripts can be obtained from the corresponding author upon request.

Received: 21 April 2021; Accepted: 28 September 2021; Published online: 27 October 2021

\section{REFERENCES}

1. Redelsperger, J.-L. et al. African monsoon multidisciplinary analysis: an international research project and field campaign. Bull. Am. Meteorol. Soc. 87, 1739-1746 (2006).

2. Martin, G. M. et al. Understanding the West African Monsoon from the analysis of diabatic heating distributions as simulated by climate models. J. Adv. Model. Earth Syst. 9, 239-270 (2017).

3. Lau, K. M., Kim, K. M., Sud, Y. C. \& Walker, G. K. A GCM study of the response of the atmospheric water cycle of West Africa and the Atlantic to Saharan dust radiative forcing. Ann. Geophys. 27, 4023-4037 (2009).

4. Lavaysse, C., Chaboureau, J.-P. \& Flamant, C. Dust impact on the West African heat low in summertime. Q. J. R. Meteorol. Soc. 137, 1227-1240 (2011).

5. Solmon, F. et al. Dust aerosol impact on regional precipitation over western Africa, mechanisms and sensitivity to absorption properties. Geophys. Res. Lett. 35, L24705 (2008).

6. Wang, W., Evan, A. T., Flamant, C. \& Lavaysse, C. On the decadal scale correlation between African dust and Sahel rainfall: The role of Saharan heat low-forced winds. Sci. Adv. 1, e1500646 (2015).

7. Sakaeda, N., Wood, R. \& Rasch, P. J. Direct and semidirect aerosol effects of southern African biomass burning aerosol. J. Geophys. Res. 116, D12205 (2011).

8. Taylor et al. Aerosol influences on low-level clouds in the West African monsoon. Atmos. Chem. Phys. 19, 8503-8522 (2019).

9. Ajoku, O., Norris, J. R. \& Miller, A. J. Observed monsoon precipitation suppression caused by anomalous interhemispheric aerosol transport. Clim. Dyn. 54, 1077-1091 (2019)

10. Pante, G., Knippertz, P., Fink, A. H. \& Kniffka, A. The potential of increasing manmade air pollution to reduce rainfall over southern West Africa. Atmos. Chem. Phys. 21, 35-55 (2021).

11. Zanis, P. et al. Fast responses on pre-industrial climate from present-day aerosols in a CMIP6 multi-model study. Atmos. Chem. Phys. 20, 8381-8404 (2020).

12. Formenti, P. et al. The aerosols, radiation and clouds in Southern Africa Field Campaign in Namibia: overview, illustrative observations, and way forward. Bull. Am. Meteorol. Soc. 100, 1277-1298 (2019).

13. Redemann, J. et al. An overview of the ORACLES (ObseRvations of Aerosols above CLouds and their intEractionS) project: aerosol-cloud-radiation interactions in the southeast Atlantic basin. Atmos. Chem. Phys. 21, 1507-1563 (2021). 
14. Haywood, J. M. et al. The CLoud-Aerosol-Radiation Interaction and Forcing: Year 2017 (CLARIFY-2017) measurement campaign. Atmos. Chem. Phys. 21, 1049-1084 (2021).

15. Shinozuka, Y. et al. Modeling the smoky troposphere of the southeast Atlantic: a comparison to ORACLES airborne observations from September of 2016. Atmos. Chem. Phys. 20, 11491-11526 (2020).

16. Giorgi, F. et al. RegCM4: model description and preliminary tests over multiple CORDEX domains. Clim. Res. 52, 7-29 (2012).

17. Mallet, M. et al. Direct and semi-direct radiative forcing of biomass burning aerosols over the Southeast Atlantic (SEA) and its sensitivity to absorbing properties: a regional climate modeling study. Atmos. Chem. Phys. 20 13191-13216 (2020).

18. Allen, R. J. et al. Observationally constrained aerosol-cloud semi-direct effects. npj Clim. Atm. Sci. 2, 16 (2019).

19. Wilcox, E. M. Stratocumulus cloud thickening beneath layers of absorbing smoke aerosol. Atmos. Chem. Phys. 10, 11769-11777 (2010).

20. Gordon, $\mathrm{H}$. et al. Large simulated radiative effects of smoke in the south-east Atlantic. Atmos. Chem. Phys. 18, 15261-15289 (2018).

21. Chung, C. E., Ramanathan, V. \& Decremer, D. Observationally constrained estimates of carbonaceous aerosol radiative forcing. Proc. Natl Acad. Sci. 109, 11624-11629 (2012).

22. Che, H., Stier, P., Gordon, H., Watson-Parris, D. \& Deaconu, L. The significant role of biomass burning aerosols in clouds and radiation in the South-eastern Atlantic Ocean. Atmos. Chem. Phys. 21, 17-33 (2021).

23. Hodnebrog, Ø., Myhre, G., Forster, P. M., Sillmann, J. \& Samset, B. H. Local biomass burning is a dominant cause of the observed precipitation reduction in southern Africa. Nat. Commun. 7, 11236 (2016).

24. Tummon, F., Solmon, F., Liousse, C. \& Tadross, M. Simulation of the direct and semidirect aerosol effects on the southern Africa regional climate during the biomass burning season. J. Geophys. Res 115, 13738 (2010).

25. Okumura, Y. \& Xie, S.-P. Interaction of the Atlantic Equatorial Cold Tongue and the African Monsoon. J. Clim. 17, 3589-3602 (2004).

26. Steinig, S., Harlaß, J., Park, W. \& Latif, M. Sahel rainfall strength and onset improvements due to more realistic Atlantic cold tongue development in a climate model. Sci. Rep. 8, 2569 (2018).

27. Lu, Z. et al. Biomass smoke from southern Africa can significantly enhance the brightness of stratocumulus over the southeastern Atlantic Ocean. Proc. Natl Acad. Sci. 115, 2924-2929 (2018).

28. Salah, Z. et al. Study of aerosol direct and indirect effects and auto-conversion processes over the West African monsoon region using a regional climate model. Adv. Atmos. Sci. 35, 182-194 (2018).

29. Samset, B. H. et al. Fast and slow precipitation responses to individual climate forcers: A PDRMIP multimodel study. Geophys. Res. Lett. 43, 2782-2791 (2016).

30. Maranan, M., Fink, A. H. \& Knippertz, P. Rainfall types over southern West Africa: objective identification, climatology and synoptic environment. Q. J. R. Meteorol. Soc. 144, 1628-1648 (2018).

31. Ajoku, O. F., Miller, A. J. \& Norris, J. R. Impacts of aerosols produced by biomass burning on the stratocumulus-to-cumulus transition in the equatorial Atlantic. Atmos. Sci. Lett. 22, e1025 (2021).

32. Tosca, M. G., Diner, D. J., Garay, M. J. \& Kalashnikova, O. V. Human-caused fires limit convection in tropical Africa: First temporal observations and attribution. Geophys. Res. Lett. 42, 6492-6501 (2015).

33. Denjean, C. et al. Unexpected biomass burning aerosol absorption enhancement explained by black carbon mixing state. Geophys. Res. Lett. 47 e2020GL089055 (2020).

34. $\mathrm{Wu}, \mathrm{H}$. et al. Vertical variability of the properties of highly aged biomass burning aerosol transported over the southeast Atlantic during CLARIFY-2017. Atmos. Chem. Phys. 20, 12697-12719 (2020).

35. Tao, W.-K., Chen, J.-P., Li, Z., Wang, C. \& Zhang, C. Impact of aerosols on convective clouds and precipitation. Rev. Geophys. 50, RG2001 (2012).

36. Jiang, J. H. et al. Contrasting effects on deep convective clouds by different types of aerosols. Nat. Commun. 9, 3874 (2018).

37. Herbert, R. J., Bellouin, N., Highwood, E. J. \& Hill, A. A. Diurnal cycle of the semidirect effect from a persistent absorbing aerosol layer over marine stratocumulus in large-eddy simulations. Atmos. Chem. Phys. 20, 1317-1340 (2020).

38. Abel, S. J. et al. Open cells exhibit weaker entrainment of free-tropospheric biomass burning aerosol into the south-east Atlantic boundary layer. Atmos. Chem. Phys. 20, 4059-4084 (2020).

39. Deetz, K. et al. Numerical simulations of aerosol radiative effects and their impact on clouds and atmospheric dynamics over southern West Africa. Atmos. Chem. Phys. 18, 9767-9788 (2018).

40. Berrisford, P. et al. The ERA-Interim archive, version 2.0. ERA report series. 1 Technical Report. ECMWF, 23 (2011).
41. van Marle, M. J. E. et al. Historic global biomass burning emissions for CMIP6 (BB4CMIP) based on merging satellite observations with proxies and fire models (1750-2015). Geosci. Model Dev. 10, 3329-3357 (2017).

42. Nogherotto, R., Tompkins, A. M., Giuliani, G., Coppola, E. \& Giorgi, F. Numerical framework and performance of the new multiple-phase cloud microphysics scheme in RegCM4.5: precipitation, cloud microphysics, and cloud radiative effects. Geosci. Model Dev. 9, 2533-2547 (2016).

43. Monterey G. I. \& Levitus, S. Seasonal Variability of Mixed Layer Depth for the World Ocean. (United States. US Department of Commerce, National Oceanic and Atmospheric Administration, National Environmental Satellite, Data, and Information Service, 1997).

44. Banzon, V., Smith, T. M., Chin, T. M., Liu, C. \& Hankins, W. A long-term record of blended satellite and in situ sea-surface temperature for climate monitoring modeling and environmental studies. Earth Syst. Sci. Data 8, 165-176 (2016).

45. Solmon, F., Nair, V. S. \& Mallet, M. Increasing Arabian dust activity and the Indian summer monsoon. Atmos. Chem. Phys. 15, 8051-8064 (2015).

46. Ghan, S. J. et al. Toward a minimal presentation of aerosols in climate models: comparative decomposition of aerosol direct, semidirect, and indirect radiative forcing. J. Clim. 25, 6461-6476 (2012).

\section{ACKNOWLEDGEMENTS}

We wish to thank G. Giuliani and the ICTP/ESP section, for maintaining and developing the RegCM4 code and providing useful assistance. We also thank A. Sayer for providing the MODIS based ACAOD observations used in Supplementary Information. We also wish to thank the AEROCLO-sA, ORACLES, and CLARIFY-2017 scientific community for providing a background to this work and promoting ideas and discussion during meetings. This work was supported by the French National Research Agency under Grant Agreement ANR-15-CE01-0014-01, AEROCLO-sA. This work was granted access to the HPC resources of CALMIP supercomputing center under the allocation 2019- p19062.

\section{AUTHOR CONTRIBUTIONS}

N.E. contributed in experiment design and modeling set up, simulation runs, and result analysis, M.M. contributed to model evaluation, result analysis and interpretation. C.F. and P.F contributed to result interpretation. F.S. designed the study, performed simulations and analysis and wrote the manuscript. All authors contributed to manuscript improvement.

\section{COMPETING INTERESTS}

The author declares no competing interests.

\section{ADDITIONAL INFORMATION}

Supplementary information The online version contains supplementary material available at https://doi.org/10.1038/s41612-021-00210-w.

Correspondence and requests for materials should be addressed to F. Solmon.

Reprints and permission information is available at http://www.nature.com/ reprints

Publisher's note Springer Nature remains neutral with regard to jurisdictional claims in published maps and institutional affiliations.

Open Access This article is licensed under a Creative Commons Attribution 4.0 International License, which permits use, sharing, adaptation, distribution and reproduction in any medium or format, as long as you give appropriate credit to the original author(s) and the source, provide a link to the Creative Commons license, and indicate if changes were made. The images or other third party material in this article are included in the article's Creative Commons license, unless indicated otherwise in a credit line to the material. If material is not included in the article's Creative Commons license and your intended use is not permitted by statutory regulation or exceeds the permitted use, you will need to obtain permission directly from the copyright holder. To view a copy of this license, visit http://creativecommons. org/licenses/by/4.0/.

(c) The Author(s) 2021, corrected publication 2021 